\title{
Cooperação em empresas inovadoras: uma análise por porte entre Brasil e países europeus selecionados*
}

\author{
Cooperation in innovative firms: an analysis by firm size between Brazil and \\ selected European countries
}

\author{
Marcelo Duarte Silva e Marisa dos Reis Azevedo Botelho**
}

\begin{abstract}
Resumo: O desenvolvimento do processo inovativo nas empresas é produto de uma série de condicionantes, como a cooperação, que pode sofrer influência do estágio de desenvolvimento dos Sistemas Nacionais de Inovação (SNI) e de variáveis intrínsecas à firma, como seu tamanho. O objetivo deste artigo é investigar as diferenças nas taxas de cooperação de empresas inovadoras e os parceiros mais frequentes na cooperação para inovação no Brasil e em países europeus selecionados, considerando um recorte por porte das firmas. Assume-se a hipótese de que a cooperação para a inovação difere segundo o porte, países e ambiente econômico. São analisados resultados da Pesquisa de Inovação Tecnológica (PINTEC), para o Brasil, e da Community Innovation Survey (CIS), para países europeus, para os períodos de 2006-08, 2009-11 e 2012-14, com o objetivo de analisar a evolução recente dos indicadores. Os resultados apontam que as taxas de cooperação crescem com o aumento do porte das empresas, que países com altas taxas de cooperação têm maior diversidade na escolha dos parceiros e que fornecedores são os parceiros mais procurados, em todos os portes de firma.
\end{abstract}

Palavras-chave: Inovação. Cooperação. Porte das empresas. Brasil. Europa

\begin{abstract}
The innovative processes in firms are the product of a series of conditions, such as cooperation, which can be influenced by the stage of development of the National Innovation Systems (NIS) and by intrinsic variables to the firm, like their size. This paper aims to investigate the differences in the rates of cooperation of innovative firms and the importance of different partners in Brazil and selected European countries, considering firms' sizes. The hypothesis is that cooperation for innovation differs according to size, countries, and the economic environment. Results of the Innovation Survey (PINTEC) for Brazil and the Community Innovation Survey (CIS) to European countries are analyzed for the periods 2006-08, 2009-11, and 2012-14. The results show that the cooperation rates improve with the increasing size of the firms, that countries with high
\end{abstract}

\footnotetext{
* Submissão: 25/11/2019. Aprovação: 23/03/2020. DOI: 10.5380/re.v41i76.70370.

** Respectivamente: (1) Doutorando em Economia PPGE/UFU. E-mail: marceloduas@outlook.com. ORCID: 0000-0002-0633-8243. (2) Professora Titular do IERI/UFU. Pesquisadora do Conselho Nacional de Desenvolvimento Científico e Tecnológico (CNPq). E-mail: botelhomr@ufu.br. ORCID: 0000-00034905-6673.
} 
rates of cooperation have greater diversity in the choice of partners, and suppliers that are the most important partners in all firm sizes.

Keywords: Innovation. Cooperation. Firm size. Brazil. Europe

JEL Code: O30; O57 


\section{Introdução}

As discussões de Schumpeter referentes à relação entre inovação e porte das empresas remete à importância do empreendedorismo individual, realçado na primeira fase do pensamento do autor (Schumpeter Marco I) e, posteriormente, na ênfase aos esforços de pesquisa e desenvolvimento (P\&D) e nas rotinas dos laboratórios de grandes empresas (GEs) como determinantes fundamentais das atividades inovativas (Schumpeter Marco II) (FARGERBERG, 2006).

No âmbito da literatura neoschumpeteriana, a discussão sobre as especificidades relacionadas ao porte, em especial as diferenças na capacidade de gerar e absorver conhecimento, tem sido empreendida por diversos autores e gerado diferentes resultados (ACS; AUDRETSCH, 1990; AUDRESTSCH, 2003; VAONA; PIANTA, 2008; FREEMAN; SOETE, 2008).

Estes e outros trabalhos recentes discutem como a capacidade de absorção de conhecimento pelas empresas, ou como aproveitar spillovers de conhecimento, valendo-se de informação externa para o desenvolvimento do processo inovativo dentro da firma, por meio de cooperação, é essencial para a inovação. O objetivo deste trabalho é investigar as diferenças nas taxas de cooperação de empresas inovadoras e os parceiros mais frequentes na cooperação para inovação, no Brasil e em países europeus selecionados, considerando um recorte por porte das firmas. Parte-se da hipótese de que há diferenças em relação ao porte das empresas, às características dos sistemas nacionais de inovação (SNIs), onde estas estão inseridas, e em função de mudanças no ambiente econômico no decorrer do ciclo econômico. Para alcançar esse objetivo, o artigo se desenvolve em duas seções, além da Introdução e Considerações Finais.

A seção 2 é dividida entre o referencial teórico, destacando os elementos que levam as empresas a realizar atividades inovativas por meio de cooperação e absorção de informação externa, e alguns resultados empíricos na literatura de cooperação e inovação. Na terceira seção, são apresentados os resultados obtidos das bases de dados de duas pesquisas: PINTEC, para o Brasil, e a CIS, para países europeus selecionados. São analisados três períodos, correspondentes aos anos de 2008, 2011 e 2014.

Entende-se que esse trabalho apresenta avanços para a literatura teórica e empírica sobre inovação, com ênfase no caso brasileiro. Ao reunir um conjunto de países e considerar o porte das empresas e o ciclo econômico, com dados que 
refletem o período pré e pós crise de 2008, é possível avançar na apreensão das especificidades dos sistemas de inovação e seus aspectos estruturais. Este tipo de abordagem é ainda incipiente na literatura, em especial a comparação entre Brasil e outros países.

\section{Diferenças na cooperação por porte da empresa}

\subsection{Revisão Teórica}

A literatura aponta para diversas variáveis que têm capacidade de impactar nos resultados inovativos das empresas: disponibilidade de crédito ou financiamento, a presença de mão de obra qualificada, o apoio do governo e de políticas públicas, a cooperação e a absorção de informação externa.

Empresas menores apresentam como características certa facilidade de responder rapidamente a mudanças, menos burocracia, mais dinamismo nas decisões e processos quando comparadas com empresas maiores, entretanto, estas últimas têm maior disponibilidade de recursos financeiros, escala maior para desenvolvimento de projetos de pesquisa e desenvolvimento (P\&D) e maior capacidade de diluir custos e diversificar áreas de atuação (ROTHWELL, 1989; NOOTEBOOM, 1994; FREEL, 2000).

As barreiras à inovação em pequenas e médias empresas (PMEs) têm origem no mercado, em restrições financeiras, na própria natureza organizacional e em relação ao conhecimento e aprendizagem (SALVADO et al., 2013). Por outro lado, as pequenas empresas têm flexibilidade e proximidade com a demanda do mercado, o que pode favorecer esforços para parcerias com clientes e consumidores com a finalidade de se desenvolver inovações de produto (NOOTEBOOM, 1994).

Havia um consenso que a cooperação para P\&D era uma estratégia difundida nas nações mais ricas, concentrada em localidades onde já havia maior intensidade de gastos em P\&D (HAGEDOORN, 2002). Tal interpretação aponta que as diferenças entre os Sistemas Nacionais de inovação teriam impacto direto na cooperação. Soma-se a isso o recente destaque sobre a importância da cooperação no desenvolvimento de atividades inovativas em empresas de todos os portes e em diversos setores. Esse processo se desenvolve de forma distinta de acordo com o porte da firma, havendo possibilidade de pequenas empresas (PEs) 
atuarem como complementares ao processo inovativo de grandes empresas (GEs) (AUDRETSCH, 2004).

Empresas menores enfrentam dificuldades derivadas de falta de recursos internos, falta de mão de obra especializada ou em quantidade necessária para manter contato contínuo com agentes externos às fronteiras da empresa (ROGERS, 2004). É válido destacar que fatores externos podem ser determinantes para o crescimento de pequenas firmas, o que sugere que as características destes é ainda mais relevante em países em desenvolvimento (NITCHER; GOLDMARK, 2009). Essa evidência sugere que as diferenças nos Sistemas Nacionais de Inovação são relevantes para explicar o comportamento das pequenas empresas.

Até meados dos anos 1990, a cooperação para inovação, ou em atividades de P\&D, era percebida como uma relação "não padrão" nos mercados, uma vez que envolve questões sensíveis como a apropriabilidade, proteção de direitos autorais e patentes (HAGEDOORN, 2002). Esse entendimento tem sido alterado recentemente, e a cooperação tem se tornado um importante componente organizacional no processo inovativo (ASCHHOFF; SCHMIDT, 2002).

A fixação de contratos de cooperação também pode ser impulsionada por necessidades organizacionais específicas: dividir os elevados custos de pesquisas e projetos de $\mathrm{P} \& \mathrm{D}$, como investimentos em laboratórios, escritórios, equipamentos e mão de obra especializados, assim como a necessidade de complementaridade e divisão do trabalho ou áreas de atuação entre empresas (HAGEDOORN, 2002). É válido destacar que joint ventures têm se tornando cada vez menos populares, em grande medida devido ao seu elevado custo de gestão e risco, ao tempo em que contratos alternativos para cooperação têm se tornando mais comuns (HAGEDOORN, 2002).

Todavia, a cooperação entre empresas que atuam no mesmo setor, ou em setores próximos ou complementares, não é a única forma de colaboração. Ela também pode ser realizada com diferentes agentes capazes de produzir diferentes resultados, como universidades, laboratórios, consumidores, fornecedores e outros (KAUFMANN; TODTLING, 2002).

\subsection{Resultados empíricos}

Diversos estudos buscam apontar e entender quais variáveis que influenciam as atividades de cooperação para inovação, seja em relação à escolha 
de parceiros, à absorção de spillovers ou informação externa, à entrada ou saída no processo inovativo, ao desenvolvimento de cooperação vertical (fornecedores, clientes) ou cooperação horizontal (universidades, concorrentes, institutos de pesquisa, consultorias, etc.).

Faria et al. (2010) analisam dados da terceira edição da CIS para Portugal e apontam que empresas com gestão de apropriabilidade, altos níveis de capacidade de absorção, elevada intensidade inovativa, grande participação de exportações nas vendas e que são parte de um grupo têm alta probabilidade de participar de cooperação para inovação. Percebe-se que justamente por praticar gestão de apropriabilidade, essas empresas acumulam aprendizagem e conseguem estabelecer parâmetros que favorecem o desenvolvimento de atividades de cooperação para inovação.

Acs et al. (1994), fazendo uso de um modelo Tobit utilizam dados do U.S. Small Business Administration's Innovation Data Base, para o ano de 1982, sugerem que há diferenças em relação ao porte das empresas na importância de spillovers e aquisição de conhecimento externo. Os autores defendem que a proximidade geográfica com universidades favorece o desenvolvimento de atividades inovativas e a absorção de spillovers.

Ainda sobre spillovers e informação externa, deve ser destacada a capacidade de absorção das firmas, bem como o posterior processamento das informações, como fatores estimuladores do processo inovativo. Tal capacidade pode ser influenciada por decisões e acontecimentos passados, e a formação de uma curva de aprendizagem, o que caracteriza sua natureza path dependent (COHEN; LEVINTHAL, 1990).

Conforme sugere Muscio (2007), em estudo sobre PMEs italianas, a capacidade de absorção, assim como a presença de mão de obra qualificada e o desenvolvimento prévio de atividades de $\mathrm{P} \& \mathrm{D}$, podem influenciar a probabilidade de as firmas cooperarem. Empresas inseridas em mercados mais competitivos têm maior probabilidade de se envolver em atividades de cooperação e em buscar conhecimento externo, sendo que a capacidade de absorção também está ligada ao nível educacional dos funcionários (FARIA et al., 2010).

Barge-Gil (2010) compara esse tipo de firma inovadora baseada em cooperação com firmas que desenvolvem atividades inovativas principalmente por via de recursos internos. O trabalho sugere que PEs fora de setores de alta 
tecnologia, que não são intensivas em $\mathrm{P} \& \mathrm{D}$, têm maior probabilidade de ser uma empresa inovadora baseada em cooperação do que GEs intensivas em P\&D. Empresas inovadoras que cooperam normalmente mantém fortes ligações com tipos específicos de agentes no contexto nacional, enquanto as demais, que não têm na cooperação o principal motor do processo inovativo, têm esforços mais dispersos entre diferentes parceiros (BARGE-GIL, 2010).

O tipo de ligação que empresas inovadoras que cooperam mantém também sofre influência de redes. Há diversos estudos que focam na atuação de redes e em sua capacidade de influenciar as decisões de cooperação para inovação e o desempenho econômico das firmas (MUSCIO, 2007; ZENG et al., 2010; VERSCHOORE; BALESTRIN, 2008; GRONUM et al., 2012). Muitos desses trabalhos apontam que há certa persistência no desenvolvimento de atividades de P\&D quando as empresas participam de redes de cooperação. Também é apontado que o impacto de participar de redes na probabilidade de inovar é maior em PEs do que em GEs.

Verschoore e Balestrin (2008) investigam o Programa de Redes de Cooperação (PRC) desenvolvido no estado do Rio Grande do Sul, uma política pública direcionada a promover desenvolvimento sustentado com base em PMEs de forma não hierarquizada. Os resultados indicam que o mais importante nas redes é o acesso a soluções, ou seja, a possibilidade de compartilhamento de informações que podem atender dificuldades individuais; assim como a cooperação gera ambiente favorável à aprendizagem organizacional e à geração de inovações, fatores estão ligados diretamente ao amadurecimento da rede.

As redes podem beneficiar as PMEs, dadas as suas limitações de recursos para cooperação, ou nos custos, que constituem barreiras ao estabelecimento de processo inovativo. Zeng et al. (2010) pesquisam PMEs industriais chinesas e assumem que há relações positivas entre a performance inovativa e as formas de cooperação: interfirma, com instituições intermediárias e com organizações de pesquisa. Diferentemente de outros estudos, os autores sugerem que a cooperação com agências do governo não tem impacto significativo para performance inovativa das PMEs. Para os autores, políticas para inovação deveriam estimular a cooperação com universidades, instituições de pesquisa e instituições intermediárias que têm impacto positivo sobre a performance inovativa, e sugerem 
que os policy markers se esforcem em criar institucionalidade e políticas que facilitem o surgimento de redes de cooperação local para PMEs.

Aschhoff e Schmidt (2008) utilizam dados do Mannheim Innovation Panel (MIP) e levantam a hipótese de que cooperação com concorrentes ou fornecedores ajudam a reduzir custos, resultando em inovação de produto. Com um modelo Tobit sugerem que a cooperação em P\&D tem efeito positivo no sucesso do processo inovativo, mas não tem efeito nas vendas de novos produtos. A cooperação com institutos de pesquisa e universidades tem impacto positivo na criação de novos produtos, mas a cooperação com fornecedores e consumidores não têm impacto algum. Todavia, o trabalho não apresenta resultados sob o recorte por porte de firma.

Belderbos et al. (2004), analisando dados da CIS para empresas alemãs, apontam que a cooperação com universidades é importante para desenvolver inovações de produtos, com impacto direto nas vendas de produtos novos para o mercado, também sendo importante como fonte de spillovers de conhecimento para impulsionar o desenvolvimento de inovações radicais.

Também com foco na colaboração com universidades, Veugelers e Cassiman (2005) apontam que GEs tendem a realizar mais cooperação com universidades que PEs, principalmente para buscar compartilhar os custos elevados de pesquisa em setores baseados em ciência. A análise dos autores, com base em dados da CIS para firmas belgas, indica que a baixa taxa de cooperação com universidades pode ser produto de uma estrutura produtiva com grande participação de PMEs e em setores não baseados em ciência.

Nieto e Santamaría (2010) propõem uma pesquisa sobre o gap entre PMEs e GEs, considerando que PMEs têm usado cooperação em P\&D para ter mais acesso a recursos, a transferências tecnológicas e para gestão de risco. A pesquisa confirma que a cooperação é muito importante para gerar entradas de spillovers no processo inovativo de PMEs, permitindo um estreitamento do gap entre PEs e GEs e que cooperação vertical contribui mais que a horizontal no desenvolvimento de inovações de produto. Entretanto, as PMEs têm menor probabilidade de se engajarem em atividades de cooperação quando comparadas com as GEs.

Alguns estudos se dedicaram a estudar a cooperação para inovação no caso brasileiro, como o de Cassiolato, Vargas e Britto (2005). Para o período mais recente e tendo como referência o porte das empresas, pode-se citar os trabalhos 
de Zucoloto e Nogueira (2006) e o de Bastos e Britto (2017). O primeiro trabalho encontra uma relação positiva entre o porte das empresas e o estabelecimento de relações de cooperação para as empresas inovadoras brasileiras, com as GEs apresentando as maiores taxas de cooperação. Ao analisar os diferentes parceiros, verificam que a distância que separa a taxa de cooperação entre PMEs e GEs é maior nas relações com universidades e centros de pesquisa e com instituições de testes, ensaios e certificações. Esse é um indicativo que as relações de cooperação mais voltadas à P\&D são menos frequentes entre as PMEs.

Bastos e Britto (2017) dedicam-se à análise das relações de cooperação de empresas com universidades e com centros de capacitação profissional e assistência técnica. Os autores mostram que houve, entre 2003 e 2011, um crescimento importante da cooperação para inovação, de 3,8\% para 16,7\%, com destaque para o fato de que o patamar inicial era muito baixo. Em relação à cooperação com universidades e com centros de capacitação profissional, também houve significativo incremento no período, de $1,5 \%$ para $6,5 \%$ e de $0,8 \%$ para $7,6 \%$, respectivamente. Um aspecto importante é que o incremento verificado em todas as taxas de cooperação é encontrado principalmente nas empresas de capital nacional e nas de menor porte (menos de 500 empregados).

Em síntese, esses resultados indicam que cooperação para inovação é relevante para as empresas, especialmente para as PMEs, uma vez que viabilizam a realização de atividades de $\mathrm{P} \& \mathrm{D}$ enfrentando dificuldades inerentes a empresas de menor porte. Vale destacar que diferentes parceiros para cooperação podem impactar de forma diferente nos resultados inovativos e que características ambientais e a atuação de políticas públicas podem proporcionar incentivos à cooperação para inovação (FARIA et al., 2010; ZENG et al., 2010).

É possível então supor que há diferenças nos resultados de cooperação das PMEs e GEs em diferentes países. Isso se deve à diversidade dos sistemas nacionais de inovação ${ }^{1}$ e de seu desenvolvimento em cada país. Com vistas a contribuir para essa discussão, a seção seguinte apresenta dados relativos à

\footnotetext{
${ }^{1}$ As diferenças quanto aos sistemas de inovação dos países, em termos de seu grau de desenvolvimento, segue a classificação proposta por Filippetti e Archibugi (2011), a saber: 1) Catching-up countries (Romênia, Bulgária, Polônia); 2) Frontrunners (Finlândia, Alemanha, Suécia, Suíça); 3) Declining (Dinamarca, Países Baixos, Reino Unido, França); 4) Lagging-behind (Hungria, Itália, Espanha, Portugal). Os países do grupo 2 são os que têm sistemas de inovação mais desenvolvidos e, juntamente o terceiro grupo, são os países com economias mais industrializadas e estruturas produtivas mais complexas.
} 
cooperação para inovação no Brasil e países europeus selecionados, respeitando o recorte por tamanho de empresa na análise.

\section{Cooperação em empresas inovadoras segundo porte e país}

A exploração dos resultados dos recentes surveys de inovação é relativamente recente, conforme indicam Fargerberger et al. (2012, p. 1180). Para os autores, esse tipo de abordagem " ...suggest a new research agenda that more adequately takes into account both the heterogeneous nature of firms' knowledge bases, innovation strategies and performance, and how they interact".

Nessa direção, será feito uso das bases de dados da PINTEC elaborada pelo Instituto Brasileiro de Geografia e Estatística, e da CIS realizada pela Agência de estatísticas europeia, Eurostat. Ambas as pesquisas seguem as determinações do Manual de Oslo, que padroniza e estabelece metodologia para mensurar inovação, o que permite a comparação dos resultados de ambas as pesquisas.

É identificada como empresa inovadora aquela que implementou inovações, de produto e/ou processo, durante o período de realização da pesquisa e, também, abrange inovações organizacionais e de marketing. O Quadro 1 apresenta os anos a que as pesquisas fazem referência:

Quadro 1 - Períodos de referência da PINTEC e CIS

\begin{tabular}{|c|c|c|}
\hline Período & PINTEC/IBGE & CIS/EUROSTAT \\
\hline 2008 & Referente ao período de 2006 a 2008 & Referente ao período de 2006 a 2008 \\
\hline 2011 & Referente ao período de 2009 a 2011 & Referente ao período de 2010 a 2012 \\
\hline 2014 & Referente ao período de 2012 a 2014 & Referente ao período de 2012 a 2014 \\
\hline
\end{tabular}

Fonte: Elaboração própria, a partir de informações dos sites da PINTEC e CIS.

A classificação quanto ao porte leva em consideração o número total de funcionários. São PEs aquelas que têm entre 10 e 49 funcionários, MEs aquelas com 50 a 249 funcionários e GEs aquelas com 250 funcionários ou mais².

\footnotetext{
${ }^{2}$ Apesar do critério de classificação de porte ser o número de funcionários, que é o mesmo empregado em grande parte da literatura, pode haver diferenças quanto ao que se considera pequena, média ou grande empresa de acordo com a quantidade de funcionários. Um exemplo é o Serviço Brasileiro de Apoio às Micro e Pequenas Empresas (SEBRAE) que considera microempresa aquelas com 1 a 19 funcionários, PEs aquela com 20 a 99 funcionários, MEs aquela com 100 a 499 funcionários e GEs como aquela com 500 funcionários ou mais.
} 
Em relação aos parceiros para cooperação são considerados um total de sete: empresas do mesmo grupo empresarial, fornecedores, clientes ou consumidores, concorrentes ou empresas do mesmo setor, consultorias ou laboratórios comerciais de P\&D, universidades ou outras instituições de ensino superior, governo.

\subsection{Taxa de cooperação}

O principal indicador capaz de mostrar a relevância da cooperação em empresas inovadoras é dado pela taxa de cooperação, apresentada na Tabela 1. Essa taxa é obtida pelo número de empresas inovadoras que realizam qualquer tipo de cooperação sobre o total de empresas inovadoras.

Tabela 1 - Taxa de cooperação para Brasil e países europeus selecionados segundo porte, em porcentagem

\begin{tabular}{lrrrrrrrrr}
\hline \multirow{1}{*}{ País } & \multicolumn{3}{c}{ PEs } & \multicolumn{3}{c}{ MEs } & \multicolumn{3}{c}{ GEs } \\
\cline { 2 - 9 } & $\mathbf{2 0 0 8}$ & $\mathbf{2 0 1 1}$ & $\mathbf{2 0 1 4}$ & $\mathbf{2 0 0 8}$ & $\mathbf{2 0 1 1}$ & $\mathbf{2 0 1 4}$ & $\mathbf{2 0 0 8}$ & $\mathbf{2 0 1 1}$ & $\mathbf{2 0 1 4}$ \\
\hline Alemanha & 13,1 & 14,8 & 13,8 & 20,7 & 26,2 & 20,1 & 42,4 & 46,9 & 40,9 \\
Áustria & 23,2 & 25,9 & 30,9 & 37,8 & 37,3 & 49,0 & 63,3 & 59,5 & 69,7 \\
Bélgica & 36,6 & 38,3 & 41,8 & 46,7 & 53,9 & 53,1 & 66,4 & 68,5 & 67,4 \\
Brasil & $\mathbf{8 , 6}$ & $\mathbf{1 4 , 0}$ & $\mathbf{1 2 , 4}$ & $\mathbf{1 2 , 7}$ & $\mathbf{2 1 , 4}$ & $\mathbf{1 9 , 5}$ & $\mathbf{2 7 , 3}$ & $\mathbf{4 0 , 2}$ & $\mathbf{3 8 , 6}$ \\
Dinamarca & 42,1 & 25,3 & 24,1 & 52,8 & 38,5 & 36,1 & 69,5 & 62,4 & 56,9 \\
Espanha & 10,3 & 15,0 & 15,5 & 22,0 & 30,8 & 30,8 & 41,2 & 49,1 & 50,4 \\
Finlândia & 27,3 & 25,0 & 27,6 & 39,0 & 36,5 & 42,6 & 67,7 & 67,0 & 70,0 \\
França & 25,1 & 18,9 & 20,1 & 36,2 & 32,4 & 37,3 & 54,4 & 51,7 & 54,6 \\
Holanda & 26,5 & 27,3 & 31,1 & 39,7 & 32,1 & 34,9 & 55,8 & 43,5 & 46,2 \\
Hungria & 22,3 & 14,2 & 23,7 & 37,2 & 29,5 & 30,3 & 60,6 & 51,3 & 47,3 \\
Itália & 9,7 & 7,8 & 12,2 & 20,6 & 13,1 & 22,6 & 41,0 & 34,6 & 37,9 \\
Noruega & 25,3 & 15,1 & 30,5 & 32,6 & 27,7 & 43,8 & 48,0 & 48,8 & 59,9 \\
Polônia & 18,8 & 12,0 & 13,1 & 35,6 & 29,5 & 27,2 & 58,2 & 51,0 & 46,5 \\
Portugal & 20,8 & 9,9 & 11,8 & 33,5 & 23,2 & 24,6 & 58,7 & 54,6 & 52,5 \\
Reino Unido & 54,3 & 43,1 & 39,5 & 59,4 & 51,1 & 47,9 & 56,3 & 55,5 & 52,8 \\
Rep. Tcheca & 16,6 & 22,0 & 22,1 & 32,8 & 43,0 & 31,9 & 54,2 & 55,2 & 55,3 \\
Suécia & 30,0 & 21,5 & 24,1 & 36,6 & 29,2 & 30,0 & 59,2 & 47,4 & 56,0 \\
Turquia & - & 8,5 & 11,3 & - & 10,3 & 17,0 & - & 26,4 & 25,3 \\
\hline Média & 24,1 & 19,9 & 22,5 & 35,0 & 31,4 & 33,3 & 54,4 & 50,7 & 51,6 \\
Desvio Padrão & 11,995 & 9,721 & 9,613 & 11,720 & 11,238 & 10,739 & 11,182 & 10,573 & 11,627 \\
\hline
\end{tabular}

Fonte: Elaboração própria, a partir de dados da CIS e PINTEC.

Nota-se que PEs inovadoras cooperam menos para inovar que GEs inovadoras. Esse padrão é verificado em todos os países analisados, o que indica 
que há maior dificuldade para PMEs estabelecerem cooperação para inovação, independentemente do SNI onde essas empresas estão inseridas. De modo geral, a análise temporal dos resultados das médias indica que há uma queda significativa de 2008 a 2011, no período pós crise internacional, com respectiva melhora em 2014, ainda que para muitos países as taxas ainda sejam menores que em 2008.

Não é observada grande diferença no desvio padrão das amostras em relação ao porte, o que indica que há uma certa simetria nas diferenças das taxas de cooperação entre PMEs e GEs nos países analisados.

Para o Brasil, há melhora no indicador entre 2008 e 2011, de 8,6\% para $14 \%$ de PEs inovadoras cooperando, tal como verificado por Bastos e Britto (2017), mas em 2014 houve queda para 12,4\%. O mesmo movimento foi verificado nas GEs e MEs do país, com melhora no segundo período seguido de pequena queda na taxa de cooperação. De modo geral os países que apresentam menores taxas de cooperação para MEs são Turquia, Brasil, Alemanha e Itália, onde a taxa chega a $22 \%$ em 2014, com resultados melhores que os verificados em PEs. Para as GEs os países com menores taxas são também Brasil, Turquia e Itália, com não mais que $41 \%$ destas empresas inovadoras realizando cooperação.

Por outro lado, os países no norte da Europa, com exceção da Alemanha, são os que apresentam melhores resultados em taxa de inovação em todos os portes de firma. É interessante notar que tais resultados não corroboram completamente com o proposto, em relação à inovação, pela classificação de Filippetti e Archibugi (2011), uma vez que empresas da Alemanha têm resultados de cooperação relativamente baixos quando comparados aos pares da Áustria, Suécia e Finlândia. A adesão à cooperação das firmas alemãs é relativamente próxima à verificada nas firmas brasileiras e italianas, em todos os portes.

De forma geral, Itália e Turquia são os países com resultados mais próximos ao brasileiro, e são os países com menores taxas de cooperação entre todos os analisados. Dinamarca e Portugal apresentam grande variação na taxa de cooperação entre os portes de empresas, com PEs cooperando pouco e GEs cooperando muito. Enquanto Reino Unido, Bélgica, Finlândia e Dinamarca têm as maiores taxas de cooperação para empresas em todos os portes. 
Sendo assim, os resultados apontam que:

- Empresas inovadoras brasileiras de todos os portes cooperam menos que as pares de outros países. Tal resultado é válido tanto para PMEs como para GEs.

- PEs cooperam menos que GEs em todos os países analisados, o que corrobora com a hipótese de dificuldades enfrentadas pelas PEs em realizar cooperação derivada da falta de mão de obra qualificada e capacidade técnica para manter contratos de colaboração (MUSCIO, 2007; ACS et al, 1994; NOOTEBOOM, 1994).

- Dos países com estrutura produtiva mais complexa e elevada taxa de inovação, a Alemanha tem baixa taxa de cooperação quando comparada aos demais.

De modo geral, os resultados reforçam as hipóteses de que empresas de menor porte têm maiores dificuldades em estabelecer cooperação, e que há significativa importância de aspectos ambientais na probabilidade de cooperar por parte de todas as empresas, o que pode ser ilustrado pela baixa taxa de cooperação em países com SNIs menos desenvolvidos como Brasil, Turquia e Polônia, e elevadas taxas em países com estruturas produtivas mais complexas e SNIs mais desenvolvidos, ainda que a Alemanha seja uma exceção a essa regra.

Alguns trabalhos sugerem o motivo da menor taxa de cooperação em PMEs, como a falta de recursos e mão de obra especializada (ROGERS, 2004), a menor capacidade de absorção de informações externas e de captação de spillovers (CHUN; MUN, 2012; MUSCIO, 2007). Outros fatores indicados na literatura (ACS et al, 1994; MUSCIO 2007, CHUN; MUN, 2012) defendem que PEs têm maior dificuldade de estabelecer cooperação por exercerem poucas atividades de P\&D interno em suas atividades inovativas. Ainda que as MEs apresentem resultados melhores que as pequenas, estes ainda são menores que os resultados observados em GEs, para todos os países analisados.

\subsection{Parceiros para cooperação}

Os resultados apresentados nas tabelas seguintes apontam para a relevância dos diferentes parceiros para cooperação. Elas exibem o porcentual de empresas inovadoras que realizam qualquer tipo de cooperação, de acordo com o porte para cada um dos parceiros indicados para cada país. 


\section{- Empresas do mesmo grupo}

A primeira das tabelas, a Tabela 2, apresenta os resultados de empresas inovadoras que cooperam e o fazem com empresas do mesmo grupo empresarial.

Tabela 2 - Empresas inovadoras que cooperam e o fazem com empresas do mesmo grupo empresarial por porte, em porcentagem

\begin{tabular}{lrrrrrrrrr}
\hline \multirow{1}{*}{ País } & \multicolumn{3}{c}{ PEs } & \multicolumn{9}{c}{ MEs } & \multicolumn{3}{c}{ GEs } \\
\cline { 2 - 9 } & $\mathbf{2 0 0 8}$ & $\mathbf{2 0 1 1}$ & $\mathbf{2 0 1 4}$ & $\mathbf{2 0 0 8}$ & $\mathbf{2 0 1 1}$ & $\mathbf{2 0 1 4}$ & $\mathbf{2 0 0 8}$ & $\mathbf{2 0 1 1}$ & $\mathbf{2 0 1 4}$ \\
\hline Alemanha & 34,38 & 20,7 & 19,6 & 37,0 & 35,3 & 32,5 & 63,2 & 58,9 & 66,7 \\
Áustria & 31,9 & 35,5 & 31,1 & 52,3 & 53,7 & 51,5 & 68,1 & 80,4 & 75,4 \\
Bélgica & 27,4 & 36,2 & 34,3 & 51,7 & 54,3 & 48,0 & 67,4 & 66,7 & 69,0 \\
Brasil & $\mathbf{5 , 5}$ & $\mathbf{3 , 3}$ & $\mathbf{1 1 , 9}$ & $\mathbf{1 8 , 6}$ & $\mathbf{1 2 , 7}$ & $\mathbf{2 1 , 6}$ & $\mathbf{4 4 , 6}$ & $\mathbf{3 1 , 8}$ & $\mathbf{4 4 , 6}$ \\
Dinamarca & 31,9 & 35,1 & 32,6 & 50,4 & 49,3 & 55,8 & 65,3 & 71,0 & 76,6 \\
Espanha & 13,3 & 16,2 & 18,4 & 29,8 & 37,2 & 40,0 & 54,6 & 60,6 & 63,5 \\
Finlândia & 29,1 & 40,5 & 30,1 & 66,1 & 68,5 & 70,8 & 86,2 & 92,6 & 93,1 \\
França & 37,3 & 29,2 & 42,9 & 56,8 & 55,0 & 58,5 & 75,6 & 74,3 & 77,0 \\
Holanda & 29,4 & 42,8 & 33,8 & 56,9 & 47,7 & 46,5 & 73,0 & 66,1 & 56,2 \\
Hungria & 19,2 & 28,5 & 19,4 & 28,3 & 45,7 & 40,9 & 52,2 & 64,2 & 61,6 \\
Itália & 11,1 & 15,1 & 12,7 & 29,7 & 34,7 & 29,2 & 61,0 & 58,1 & 54,0 \\
Noruega & 42,0 & 45,4 & 41,2 & 50,2 & 53,8 & 61,3 & 72,1 & 74,3 & 76,1 \\
Polônia & 12,1 & 29,7 & 29,2 & 22,6 & 30,7 & 31,8 & 49,0 & 59,2 & 60,8 \\
Portugal & 14,9 & 23,7 & 20,1 & 38,8 & 45,1 & 39,2 & 70,6 & 65,1 & 62,3 \\
Reino Unido & 44,6 & 44,9 & 46,9 & 50,9 & 52,0 & 50,0 & 64,3 & 63,1 & 64,2 \\
Rep. Tcheca & 30,1 & 25,0 & 31,2 & 40,9 & 40,0 & 40,8 & 64,6 & 66,5 & 67,6 \\
Suécia & 57,2 & 47,3 & 49,2 & 66,4 & 74,0 & 71,9 & 85,4 & 89,2 & 89,5 \\
Turquia & - & 67,6 & 85,1 & - & 54,2 & 70,4 & - & 71,3 & 71,6 \\
\hline Média & 27,727 & 32,588 & 32,760 & 43,964 & 46,884 & 47,817 & 65,703 & 67,400 & 68,327 \\
Desvio Padrão & 13,684 & 14,750 & 17,091 & 14,603 & 14,052 & 14,859 & 11,443 & 13,235 & 11,934 \\
\hline
\end{tabular}

Fonte: Elaboração própria, a partir de dados da CIS e PINTEC.

As médias apontam que houve significativa melhora na participação de cooperação com empresas do mesmo grupo no decorrer do período analisado. Há significativa diferença no desvio padrão amostral entre as PEs e GEs, o que indica que há maior discrepância entre as taxas de empresas que cooperam e o fazem com empresas do mesmo grupo, e que as diferenças ambientais e SNIs tem peso maior na decisão das PEs de cooperar com empresas do mesmo grupo em relação às GEs. Como apontando por Filippetti e Archibugi (2011), alguns fatores estruturais de um SNI são a qualidade e competência dos recursos humanos, setores 
especializados em alta tecnologia, bem como sistema financeiro mais desenvolvido.

Brasil, Itália, Espanha e Hungria são os países com menor participação de PEs inovadoras que cooperam com empresas do mesmo grupo. Um resultado muito parecido é encontrado para as MEs, onde Brasil é novamente o país com menor participação de cooperação com empresas do mesmo grupo, seguido de Itália e Polônia em todo período. As MEs espanholas apresentam um significativo aumento nesta taxa entre 2008 e 2014. As GEs brasileiras também são as que menos cooperam com esse parceiro na comparação internacional, e têm grande oscilação na participação, pois em 2008 e 2014 os indicadores estavam próximos de $44 \%$, enquanto em 2011 foi de $32 \%$.

Há grande diferença no indicador de PEs e GEs, mesmo em países com maiores participações. Isso pode ser explicado quer seja por GEs normalmente já participarem de holdings ou grupos empresariais, enquanto PEs inovadoras tendem a ser resultado de comportamentos empreendedores e start ups, não fazendo necessariamente parte de grupos empresariais. A média dos dados para os países apresentam resultados maiores que a taxa de cooperação, o que indica que este é um dos principais parceiros para cooperação.

A hipótese de coexistência e retroalimentação de PEs e GEs no processo inovativo também pode ser destacada como fator explicativo. Evidências apontam que a busca pelo desenvolvimento tecnológico levou a uma forma de complementaridade dinâmica ou divisão do trabalho em empresas de diferentes portes (RIZZONNI, 1994). Essa hipótese pode ser exemplificada na existência de relações entre PEs e GEs para desenvolvimento de projetos de P\&D específicos ou compartilhamento tecnológico, muito presentes também em processos que resultam em aquisição ou fusão entre empresas pequenas e grandes (AUDRETSCH, 2004). Por esses fatores, é possível identificar que empresas que fazem parte de grupo, frequentemente, têm maior probabilidade de realizar cooperação para inovação (FARIA et al., 2010).

\section{- Fornecedores de equipamentos, materiais, componentes ou softwares}

A Tabela 3 apresenta a taxa de empresas inovadoras que cooperam e o fazem com fornecedores de equipamentos, materiais, componentes ou softwares. As médias apontam que a cooperação com fornecedores é mais frequente que com 
empresas do mesmo grupo. GEs cooperem mais com esse parceiro que PMEs, ainda que a diferença seja pequena. $\mathrm{O}$ desvio padrão tem valor maior para PMEs que para as GEs, o que indica que características dos SNIs podem ter maior peso para a cooperação com fornecedores para PMEs.

Tabela 3 - Empresas inovadoras que cooperam e o fazem com fornecedores de equipamentos, materiais, componentes ou softwares por porte, em porcentagem

\begin{tabular}{lccccccccc}
\hline \multirow{1}{*}{ País } & \multicolumn{3}{c}{ PEs } & \multicolumn{3}{c}{ MEs } & \multicolumn{3}{c}{ GEs } \\
\cline { 2 - 10 } & $\mathbf{2 0 0 8}$ & $\mathbf{2 0 1 1}$ & $\mathbf{2 0 1 4}$ & $\mathbf{2 0 0 8}$ & $\mathbf{2 0 1 1}$ & $\mathbf{2 0 1 4}$ & $\mathbf{2 0 0 8}$ & $\mathbf{2 0 1 1}$ & $\mathbf{2 0 1 4}$ \\
\hline Alemanha & 32,89 & 36,71 & 30,65 & 36,52 & 41,93 & 31,06 & 47,21 & 56,39 & 59,67 \\
Áustria & 52,11 & 57,35 & 49,53 & 58,92 & 56,94 & 62,60 & 67,39 & 69,59 & 71,08 \\
Bélgica & 69,09 & 67,30 & 78,00 & 70,89 & 68,67 & 75,08 & 73,96 & 71,39 & 77,71 \\
Brasil & $\mathbf{6 3 , 6 8}$ & $\mathbf{6 9 , 6 8}$ & $\mathbf{7 4 , 0 8}$ & $\mathbf{6 3 , 6 2}$ & $\mathbf{7 3 , 0 4}$ & $\mathbf{7 4 , 9 5}$ & $\mathbf{6 7 , 7 9}$ & $\mathbf{7 5 , 2 9}$ & $\mathbf{7 2 , 2 4}$ \\
Dinamarca & 71,23 & 73,80 & 64,40 & 81,38 & 80,00 & 78,63 & 83,47 & 82,84 & 85,52 \\
Espanha & 43,58 & 42,73 & 42,36 & 49,76 & 42,88 & 45,89 & 58,86 & 58,18 & 57,49 \\
Finlândia & 93,88 & 82,07 & 76,60 & 94,52 & 85,56 & 86,08 & 94,64 & 94,88 & 91,13 \\
França & 56,48 & 59,59 & 54,06 & 58,90 & 55,89 & 56,03 & 68,77 & 68,47 & 66,20 \\
Holanda & 76,00 & 69,23 & 68,99 & 80,79 & 77,84 & 70,26 & 82,33 & 77,41 & 72,17 \\
Hungria & 74,36 & 69,44 & 64,86 & 56,76 & 62,91 & 64,77 & 62,87 & 67,16 & 62,26 \\
Itália & 57,77 & 50,99 & 55,17 & 53,85 & 58,29 & 42,18 & 56,27 & 57,76 & 55,95 \\
Noruega & 55,41 & 56,92 & 68,76 & 56,50 & 62,08 & 77,84 & 77,05 & 74,29 & 81,25 \\
Polônia & 81,84 & 59,35 & 47,50 & 76,12 & 64,43 & 54,73 & 81,73 & 74,66 & 69,59 \\
Portugal & 77,50 & 67,94 & 50,79 & 75,45 & 64,76 & 54,83 & 79,37 & 79,13 & 65,45 \\
Reino Unido & 65,60 & 56,41 & 64,19 & 67,55 & 61,54 & 67,78 & 70,70 & 68,23 & 69,09 \\
Rep. Tcheca & 71,06 & 71,21 & 61,84 & 75,58 & 66,76 & 58,03 & 78,35 & 75,76 & 69,69 \\
Suécia & 78,14 & 83,72 & 73,62 & 82,43 & 85,94 & 81,13 & 84,48 & 92,00 & 89,09 \\
Turquia & - & 59,89 & 86,68 & - & 64,75 & 89,64 & - & 70,79 & 80,98 \\
\hline Média & 65,919 & 63,018 & 61,784 & 67,032 & 65,234 & 65,083 & 72,661 & 73,012 & 72,031 \\
Desvio Padrão & 15,017 & 12,219 & 14,228 & 14,561 & 12,298 & 15,868 & 11,955 & 10,390 & 10,437 \\
\hline
\end{tabular}

Fonte: Elaboração própria, a partir de dados da CIS e PINTEC.

As PEs que têm menor participação na cooperação com fornecedores dentre os países analisados são da Alemanha e Espanha. Para as MEs, Alemanha, Espanha e Itália são os países onde a cooperação com fornecedores é menos observada, com taxas em torno de $45 \%$ para Espanha e $31 \%$ para Alemanha, ambos em 2014. Nesses países há queda na participação de cooperação com esse parceiro entre 2008 e 2014. As GEs são as que mais cooperam com fornecedores para a maioria dos países e na maior parte do tempo. Novamente Alemanha, Itália e Espanha apresentam as menores taxas de cooperação com fornecedores, menores que $60 \%$ em todo período analisado, e com pouca variação no tempo. 
Em 2014, os países onde as PEs inovadoras que cooperam mais se destacam nesse tipo de cooperação são Bélgica, Turquia, Finlândia e Brasil. As MEs e GEs de Finlândia, Suécia e Dinamarca também são as que mais cooperam com fornecedores, com participação de mais de $80 \%$.

Empresas brasileiras cooperam com maior frequência com fornecedores que com empresas do mesmo grupo, e é observado aumento contínuo no decorrer do tempo na cooperação das empresas brasileiras com o primeiro. Não há grande diferença entre os portes das empresas e, na verdade, em 2014 é observada maior participação deste tipo de cooperação em PMEs do que em GEs no Brasil. Para todos os tamanhos de firma no Brasil, a taxa de empresas inovadoras que cooperam e o fazem com fornecedores é de cerca de $63 \%$ a $75 \%$, o que coloca o país ao lado daqueles onde esse tipo de cooperação é relativamente mais importante, como Finlândia, Suécia e Dinamarca. Para esse indicador, não há um padrão que separe os países de maneira clara, como é observado na taxa de cooperação geral.

A cooperação com fornecedores tem grande impacto em inovação de produto, mesmo que isso ocorra de forma incremental (KAUFMANN; TODTLING, 2002). Também deve ser considerado que tal cooperação pode ser traduzida em colaboração para desenvolvimento de máquinas e equipamentos sob encomenda, principalmente em setores de alta tecnologia (FARIA et al., 2010).

\section{- Clientes ou consumidores}

A Tabela 4 mostra os resultados para cooperação com clientes ou consumidores, discriminando as empresas por porte. As médias dos dados permitem supor que esse tipo de cooperação é mais frequentemente observada que com empresas do mesmo grupo para PMEs, mas não para GEs. A cooperação com tal parceiro é menos frequente que a com fornecedores. Também não são observadas significativas discrepâncias na média dos resultados para PMEs e GEs, apenas destacando que houve queda das médias durante o período 2008-2014. 
Tabela 4 - Empresas inovadoras que cooperam com clientes ou consumidores por porte, em porcentagem

\begin{tabular}{lrrrrrrrrr}
\hline \multirow{1}{*}{ País } & \multicolumn{3}{c}{ PEs } & \multicolumn{1}{c}{ MEs } & \multicolumn{3}{c}{ GEs } \\
\cline { 2 - 10 } & $\mathbf{2 0 0 8}$ & $\mathbf{2 0 1 1}$ & $\mathbf{2 0 1 4}$ & $\mathbf{2 0 0 8}$ & $\mathbf{2 0 1 1}$ & $\mathbf{2 0 1 4}$ & $\mathbf{2 0 0 8}$ & $\mathbf{2 0 1 1}$ & $\mathbf{2 0 1 4}$ \\
\hline Alemanha & 56,77 & 34,08 & 29,59 & 47,6 & 34,17 & 33,57 & 54,53 & 50,75 & 45,11 \\
Áustria & 40,28 & 48,41 & 38,13 & 38,13 & 47,22 & 28,84 & 54,59 & 61,08 & 46,84 \\
Bélgica & 69,09 & 39,06 & 34,38 & 70,89 & 43,88 & 35,21 & 73,96 & 47,49 & 43,03 \\
Brasil & $\mathbf{4 6 , 1}$ & $\mathbf{5 5 , 2}$ & $\mathbf{7 5 , 3 2}$ & $\mathbf{4 1 , 2 3}$ & $\mathbf{5 8 , 2 4}$ & $\mathbf{6 5 , 4 8}$ & $\mathbf{5 2 , 4}$ & $\mathbf{6 5 , 3 3}$ & $\mathbf{6 5 , 0 0}$ \\
Dinamarca & 59,78 & 48,62 & 43,20 & 58,22 & 54,25 & 57,26 & 63,64 & 66,86 & 71,03 \\
Espanha & 24,16 & 31,17 & 32,61 & 26,1 & 31,05 & 29,27 & 33,54 & 34,24 & 33,13 \\
Finlândia & 92,68 & 81,31 & 75,55 & 95,3 & 83,16 & 77,12 & 94,64 & 96,28 & 87,19 \\
França & 42,87 & 34,1 & 28,81 & 49,27 & 30,98 & 32,40 & 55,6 & 39,98 & 37,55 \\
Holanda & 58,08 & 46,22 & 49,80 & 60,32 & 53,61 & 51,05 & 63,26 & 53,14 & 49,28 \\
Hungria & 48,58 & 44,91 & 37,84 & 39,31 & 47,48 & 33,81 & 45,59 & 48,53 & 40,88 \\
Itália & 33,42 & 35,17 & 21,47 & 29,76 & 28,4 & 14,79 & 39,52 & 33,88 & 25,31 \\
Noruega & 48,24 & 61,68 & 52,15 & 49,85 & 57,5 & 50,70 & 54,92 & 63,81 & 55,11 \\
Polônia & 52,13 & - & 21,36 & 52,77 & - & 27,80 & 49,94 & & 34,64 \\
Portugal & 68,01 & 55,53 & 40,67 & 60,47 & 52,63 & 35,71 & 62,7 & 55,34 & 35,60 \\
Reino Unido & 78,59 & 68,67 & 65,90 & 79,21 & 62,79 & 63,34 & 79,72 & 64,24 & 63,71 \\
Rep. Tcheca & 64,5 & 48,88 & 39,90 & 49,05 & 40,31 & 25,66 & 62,45 & 44,24 & 33,40 \\
Suécia & 72,29 & 83,41 & 67,70 & 62,06 & 81,85 & 66,38 & 69,85 & 87,2 & 70,55 \\
Turquia & - & 52,19 & 82,68 & - & 51,69 & 76,76 & - & 63,08 & 68,82 \\
\hline Média & 56,210 & 51,095 & 46,503 & 53,502 & 50,542 & 44,732 & 59,462 & 57,381 & 50,344 \\
Desvio Padrão & 17,137 & 15,552 & 19,226 & 17,482 & 15,853 & 19,035 & 14,798 & 16,762 & 17,104 \\
\hline
\end{tabular}

Fonte: Elaboração própria, a partir de dados da CIS e PINTEC.

As PEs de Espanha, Itália e França são as que menos realizam cooperação com consumidores, e nos dois últimos períodos é observada contínua queda na participação desse tipo de cooperação, chegando a cerca de $21 \%$ e $28 \%$ em 2014 , respectivamente. As MEs inovadoras italianas que cooperam também são as que menos o fazem com esse tipo de parceiro, apenas 14\% em 2014, seguidas das de República Tcheca, Polônia e Espanha. Ainda que as GEs inovadoras que cooperam da Itália, Espanha e França o façam mais com clientes que as PMEs destes mesmos países, elas cooperam menos que as GEs dos demais países.

Os países que têm empresas que mais cooperam com clientes são Finlândia, Turquia, Dinamarca, Suécia e Reino Unido, para todos os portes de empresas. Ainda assim, há grande variação na participação deste tipo de parceiro na cooperação desses países durante o período, com queda na participação de empresas de todos os portes para Finlândia e Reino Unido, e aumento para Turquia em todos os portes de empresas e para GEs da Dinamarca e Suécia. 
O Brasil registra aumento na participação de clientes na cooperação para inovação para todos os portes de empresas. Para PEs brasileiras há aumento da cooperação, e em MEs e GEs chegam a cerca de 65\% em 2014. Esse resultado chama a atenção, pois no caso brasileiro as PEs têm cooperado mais com clientes ou consumidores que as GEs, o que corrobora os achados de Zeng et al. (2010) que identifica que cooperação do tipo vertical (aquela com fornecedores ou consumidores) tem impacto significativamente positivo sobre resultados em inovações de processo para PMEs. As taxas de cooperação com consumidores também são significativamente maiores que as taxas de cooperação geral, o que indica ser esse um dos principais parceiros para cooperação no Brasil e na maioria dos demais países, corroborando para a hipótese dos autores acima citados.

\section{- Concorrentes ou empresas do mesmo setor}

Cooperação com concorrentes podem se dar em joint ventures, parcerias ou outros tipos de contratos ou subcontratação (como outsourcing), que visam dividir custos inerentes ao processo inovativo (HAGEDOORN, 2002). A Tabela 5 apresenta a parcela de empresas inovadoras que cooperam e o fazem com concorrentes. As médias da tabela sugerem que há pequena diferença entre a taxa de cooperação com concorrentes por porte de empresa, observando em todos os portes uma queda contínua de participação de cooperação com esse parceiro.

Tabela 5 - Empresas inovadoras que cooperam e o fazem concorrentes ou empresas do mesmo setor por porte, em porcentagem

\begin{tabular}{lrcccccccc}
\hline \multirow{2}{*}{ País } & \multicolumn{3}{c}{ PEs } & \multicolumn{3}{c}{ MEs } & \multicolumn{3}{c}{ GEs } \\
\cline { 2 - 10 } & $\mathbf{2 0 0 8}$ & $\mathbf{2 0 1 1}$ & $\mathbf{2 0 1 4}$ & $\mathbf{2 0 0 8}$ & $\mathbf{2 0 1 1}$ & $\mathbf{2 0 1 4}$ & $\mathbf{2 0 0 8}$ & $\mathbf{2 0 1 1}$ & $\mathbf{2 0 1 4}$ \\
\hline Alemanha & 25,5 & 21,37 & 15,67 & 19,32 & 15,4 & 13,5 & 22,61 & 23,38 & 26,36 \\
Áustria & 25,7 & 34,15 & 34,26 & 19,13 & 31,69 & 19,9 & 26,33 & 37,89 & 26,48 \\
Bélgica & 23,48 & 25,64 & 11,71 & 32,66 & 18,88 & 13,3 & 32,29 & 35,1 & 19,50 \\
Brasil & $\mathbf{1 7 , 1 4}$ & $\mathbf{2 5 , 0 4}$ & $\mathbf{2 7 , 6 2}$ & $\mathbf{1 5 , 5}$ & $\mathbf{2 4 , 7 5}$ & $\mathbf{2 3 , 0}$ & $\mathbf{1 4 , 4 2}$ & $\mathbf{2 9 , 1 3}$ & $\mathbf{2 5 , 8 5}$ \\
Dinamarca & 26,38 & 22,56 & 18,99 & 21,91 & 24,38 & 23,4 & 38,43 & 40,83 & 46,90 \\
Espanha & 17,78 & 20,89 & 21,42 & 17,85 & 22,04 & 19,6 & 25,47 & 31,67 & 25,72 \\
Finlândia & 80,43 & 72,22 & 47,01 & 79,37 & 66,04 & 52,8 & 81,25 & 80 & 71,92 \\
França & 23,37 & 22,05 & 18,29 & 25,35 & 16,93 & 15,9 & 33,05 & 25,98 & 24,96 \\
Holanda & 29,28 & 30,85 & 26,20 & 29,13 & 24,95 & 25,8 & 33,49 & 30,13 & 29,86 \\
Hungria & 32,38 & 35,97 & 27,53 & 29,98 & 28,78 & 20,3 & 32,72 & 30,88 & 20,75 \\
Itália & 32,7 & 30,06 & 27,92 & 26,74 & 30,51 & 21,4 & 25,3 & 32,24 & 25,17 \\
Noruega & 19,04 & 29,48 & 22,81 & 18,43 & 32,92 & 26,1 & 22,13 & 38,1 & 34,66 \\
\hline (continua) & \multicolumn{1}{c}{} & & & & & & & &
\end{tabular}


(continuação)

\begin{tabular}{lrrrrrrrrr}
\hline \multirow{1}{*}{ País } & \multicolumn{3}{c}{ PEs } & \multicolumn{3}{c}{ MEs } & \multicolumn{3}{c}{ GEs } \\
\cline { 2 - 10 } & $\mathbf{2 0 0 8}$ & $\mathbf{2 0 1 1}$ & $\mathbf{2 0 1 4}$ & $\mathbf{2 0 0 8}$ & $\mathbf{2 0 1 1}$ & $\mathbf{2 0 1 4}$ & $\mathbf{2 0 0 8}$ & $\mathbf{2 0 1 1}$ & $\mathbf{2 0 1 4}$ \\
\hline Polônia & 32,06 & 18,58 & 17,64 & 27,7 & 22,14 & 15,3 & 28,71 & 29,2 & 24,29 \\
Portugal & 34,82 & 30,42 & 22,70 & 29,33 & 25,4 & 16,6 & 33,73 & 33,98 & 20,42 \\
Reino Unido & 30,96 & 30,4 & 32,96 & 23,82 & 23,34 & 27,8 & 24,74 & 27,67 & 26,13 \\
Rep. Tcheca & 44,36 & 25,56 & 11,61 & 24,52 & 17,83 & 9,4 & 30,84 & 18,18 & 10,10 \\
Suécia & 26,47 & 60,1 & 37,59 & 26,78 & 60,85 & 33,3 & 36,72 & 67,6 & 42,91 \\
Turquia & - & 44,15 & 72,90 & - & 32,3 & 58,0 & - & 41,12 & 45,29 \\
\hline Média & 30,697 & 32,194 & 27,489 & 27,501 & 28,841 & 24,187 & 31,896 & 36,282 & 30,405 \\
Desvio Padrão & 14,510 & 13,988 & 14,552 & 14,241 & 13,668 & 12,798 & 14,087 & 15,008 & 13,939 \\
\hline
\end{tabular}

Fonte: Elaboração própria, a partir de dados da CIS e PINTEC.

As PEs do Brasil são as que menos realizam cooperação com esse tipo de parceiro em 2008, com aumento na participação destas empresas na cooperação com concorrentes durante o período, para cerca de 27\% em 2014. Esse movimento também é registrado na Suécia, República Tcheca, Áustria e Reino Unido, porém é contrário ao observado nos demais países, que registram queda na participação.

Para as MEs, observa-se que aquelas que menos cooperam com concorrentes são as do Brasil, Espanha e Alemanha. Por outro lado, Finlândia e Turquia apresentam elevada participação de cooperação com concorrentes. As GEs desses dois países também são as que mais realizaram cooperação com esse tipo de parceiro, seguidas da Suécia e Dinamarca. GEs brasileiras têm taxa menor em 2008, com grande aumento em 2011 e posterior queda em 2014, mas ainda assim as GEs de República Tcheca, Portugal e Hungria apresentam menor cooperação com concorrentes que as brasileiras em 2014.

A cooperação com concorrentes é relativamente pouco importante para a maioria das empresas na maioria dos países. Não há um padrão que separe países com SNIs maduros dos demais. O Brasil tem aumento significativo da importância de cooperação com concorrentes em 2014, ultrapassando países com maior taxa de cooperação (conforme Tabela 1), como França e República Tcheca.

\section{- Consultorias, laboratórios comerciais ou institutos privados de P\&D}

A cooperação com consultorias, laboratórios comerciais ou institutos privados de P\&D (Tabela 6) apresenta desvio padrão entre os países maior para GEs do que para PEs, o que é pode indicar que as primeiras são mais sensíveis a variações ambientais e dos SNIs na realização esse tipo de cooperação. As médias 
dos resultados apontam que a cooperação com consultorias é mais frequente entre GEs inovadoras que cooperam do que com PMEs, sendo que, em média, 35\% e $42 \%$ destas cooperam com esse parceiro, enquanto as GEs têm resultados maiores, de mais de $50 \%$. De modo geral, esse tipo de parceiro é menos frequente que fornecedores, consumidores e empresas do mesmo grupo.

Tabela 6 - Empresas inovadoras que cooperam com consultorias, laboratórios comerciais ou institutos privados de $P \& D$ por porte, em porcentagem

\begin{tabular}{lrrrrrrrrr}
\hline \multirow{1}{*}{ País } & \multicolumn{3}{c}{ PEs } & \multicolumn{3}{c}{ MEs } & \multicolumn{3}{c}{ GEs } \\
\cline { 2 - 10 } & $\mathbf{2 0 0 8}$ & $\mathbf{2 0 1 1}$ & $\mathbf{2 0 1 4}$ & $\mathbf{2 0 0 8}$ & $\mathbf{2 0 1 1}$ & $\mathbf{2 0 1 4}$ & $\mathbf{2 0 0 8}$ & $\mathbf{2 0 1 1}$ & $\mathbf{2 0 1 4}$ \\
\hline Alemanha & 31,43 & 23,71 & 22,45 & 18,78 & 25,53 & 28,78 & 29,86 & 37,5 & 41,59 \\
Áustria & 31,13 & 31,96 & 30,40 & 42,75 & 33,33 & 38,03 & 51,21 & 53,61 & 50,71 \\
Bélgica & 42,13 & 32,23 & 29,21 & 47,69 & 37,76 & 38,03 & 61,11 & 49,85 & 57,28 \\
Brasil & $\mathbf{3 1 , 5 6}$ & $\mathbf{3 1 , 0 8}$ & $\mathbf{3 3 , 4 0}$ & $\mathbf{2 8 , 3 1}$ & $\mathbf{3 6 , 6 1}$ & $\mathbf{3 4 , 9 2}$ & $\mathbf{3 2 , 0 5}$ & $\mathbf{3 8 , 9 2}$ & $\mathbf{3 7 , 1 9}$ \\
Dinamarca & 41,04 & 52,98 & 45,57 & 50,23 & 56,99 & 47,29 & 65,7 & 72,78 & 62,07 \\
Espanha & 21,43 & 23,88 & 22,36 & 26,23 & 26,39 & 24,97 & 38,29 & 41,67 & 35,70 \\
Finlândia & 69,99 & 54,29 & 49,53 & 81,46 & 71,39 & 68,40 & 89,29 & 85,12 & 86,21 \\
França & 24,83 & 32,75 & 29,78 & 37,43 & 33,63 & 38,17 & 49,16 & 50,47 & 49,93 \\
Holanda & 31,98 & 30,5 & 24,20 & 45,49 & 43,2 & 29,49 & 61,4 & 51,05 & 45,51 \\
Hungria & 30,73 & 39,71 & 32,09 & 43,49 & 52,23 & 35,23 & 58,09 & 60,29 & 44,03 \\
Itália & 41,67 & 39,94 & 46,46 & 44,6 & 48,02 & 44,32 & 50,6 & 51,94 & 49,93 \\
Noruega & 42,76 & 52,83 & 49,91 & 57,1 & 58,33 & 63,07 & 64,75 & 70,48 & 75,00 \\
Polônia & 23,66 & 22,07 & 13,39 & 26,72 & 24,93 & 24,71 & 36,3 & 43,11 & 42,16 \\
Portugal & 34,45 & 35,47 & 18,09 & 42,76 & 38,9 & 28,96 & 58,33 & 49,51 & 40,31 \\
Reino Unido & 26,64 & 34,05 & 35,10 & 30,54 & 32,93 & 36,86 & 42,05 & 45,45 & 43,38 \\
Rep. Tcheca & 37,86 & 27,11 & 25,91 & 39,34 & 29,94 & 19,85 & 50,77 & 40,61 & 35,05 \\
Suécia & 53,69 & 56,06 & 45,29 & 66,81 & 61,21 & 63,64 & 72,24 & 77,6 & 68,73 \\
Turquia & - & 40,76 & 69,84 & - & 45,93 & 63,14 & - & 60,98 & 71,18 \\
\hline Média & 36,293 & 36,743 & 34,610 & 42,925 & 42,069 & 40,437 & 53,600 & 54,497 & 51,998 \\
Desvio Padrão & 11,986 & 10,904 & 14,049 & 15,565 & 13,542 & 14,941 & 15,389 & 13,973 & 14,911 \\
\hline
\end{tabular}

Fonte: Elaboração própria, a partir de dados da CIS e PINTEC.

A Finlândia é o país com maior parcela de empresas inovadoras que cooperam com consultorias, entre todos os países analisados. Outros países que têm PEs com taxas mais altas com esse parceiro são Suécia, Dinamarca e Noruega, em todos os períodos analisados. Há maior participação de PEs turcas em 2014 na cooperação com consultorias. Nesse mesmo porte de empresa, os países que têm menor participação são Polônia, Espanha e Alemanha, com porcentagens que não ultrapassam 32\% entre 2008-2014, e chegam a cerca de 13\% para Polônia em 2014. As PEs brasileiras também não têm grande envolvimento em cooperação 
com esse tipo de parceiro, dado que apenas cerca de $31 \%$ dessas empresas estão envolvidas neste tipo de cooperação, em todos os períodos analisados.

As médias e GEs de Suécia, Finlândia, Dinamarca e Noruega são as que têm maior participação na cooperação com consultorias entre todos os países, havendo também grande participação de empresas do mesmo porte na Turquia. Percebe-se que, apesar de Turquia e Itália apresentarem resultados maiores que com os demais tipos de cooperação, o padrão de maior participação dos países nórdicos europeus permanece. Empresas de países do Leste e Sul europeus, juntamente com o Brasil, são aquelas que têm menor envolvimento em cooperação com esse tipo de parceiro, independentemente do porte de empresa. Nesse sentido os resultados apontam para uma aproximação da classificação proposta por Filippetti e Archibugi (2011), ao contrapor países com estruturas produtivas mais complexas e os países com essas estruturas menos desenvolvidas em grupos distintos.

Também é notável que PEs cooperam menos com esse tipo de parceiro que as GEs, seguindo o padrão da cooperação com empresas do mesmo grupo empresarial, apresentado na Tabela 2 . As baixas porcentagens demonstram que, para a maioria dos países, esse tipo de cooperação não tem muita importância. A exceção são os países nórdicos, principalmente para GEs, pois apresentam mais da metade de suas empresas inovadoras que cooperam envolvidas com esse tipo de parceiro.

\section{- Universidades ou outras instituições de ensino superior}

As Universidades e instituições de ensino superior, além de formadoras de mão de obra especializada, têm papel determinante na geração de conhecimento. Os investimentos feitos em investigação em ciência básica permitem avanços tecnológicos posteriores e forte influência na conformação de trajetórias tecnológicas, muito embora exijam custos elevados para execução destes tipos de pesquisas. A proximidade com Universidade pode favorecer o aproveitamento de spillovers de mão de obra especializada e de ingresso em novos projetos (MOWERY; SAMPAT, 2006)

A Tabela 7 apresenta os resultados de cooperação com universidades. A análise das médias indica que a cooperação com universidades é uma das mais recorrentes, junto com a cooperação com empresas do mesmo grupo e com fornecedores. De forma geral, mais de $30 \%$ das PEs inovadoras que cooperam o fazem com universidades, valor que sobe para cerca de $40 \%$ para MEs, e para 
aproximadamente $60 \%$ para GEs, em todos os períodos analisados. O desvio padrão é maior para GEs que para PEs, indicando uma maior sensibilidade às características locais dos SNIs que as PEs.

Tabela 7 - Empresas inovadoras que cooperam com Universidades ou outras instituições de ensino superior por porte, em porcentagem

\begin{tabular}{lrrrrrrrrrr}
\hline \multirow{1}{*}{ País } & \multicolumn{3}{c}{ PEs } & \multicolumn{1}{c}{ MEs } & \multicolumn{3}{c}{ GEs } \\
\cline { 2 - 10 } & $\mathbf{2 0 0 8}$ & $\mathbf{2 0 1 1}$ & $\mathbf{2 0 1 4}$ & $\mathbf{2 0 0 8}$ & $\mathbf{2 0 1 1}$ & $\mathbf{2 0 1 4}$ & $\mathbf{2 0 0 8}$ & $\mathbf{2 0 1 1}$ & $\mathbf{2 0 1 4}$ \\
\hline Alemanha & 48,02 & 56,45 & 58,17 & 52,79 & 59,29 & 69,73 & 68,16 & 73,92 & 78,14 \\
Áustria & 41,62 & 41,9 & 35,43 & 56,23 & 54,8 & 49,59 & 70,05 & 77,84 & 75,15 \\
Bélgica & 32,83 & 30,84 & 31,71 & 48,17 & 38,16 & 38,64 & 59,72 & 55,75 & 59,44 \\
Brasil & $\mathbf{2 7 , 7 2}$ & $\mathbf{2 3 , 0 4}$ & $\mathbf{2 2 , 3 6}$ & $\mathbf{3 0 , 6 8}$ & $\mathbf{3 6 , 3 1}$ & $\mathbf{2 6 , 4 1}$ & $\mathbf{4 7 , 9 2}$ & $\mathbf{4 8 , 4 4}$ & $\mathbf{4 4 , 2 2}$ \\
Dinamarca & 25,43 & 28,68 & 34,81 & 33,33 & 39,73 & 40,17 & 60,33 & 56,8 & 65,52 \\
Espanha & 26,89 & 30,9 & 30,84 & 33,67 & 34,76 & 33,38 & 48,42 & 52,27 & 47,66 \\
Finlândia & 68,67 & 63,38 & 50,26 & 80,42 & 78,88 & 68,16 & 92,86 & 94,88 & 91,13 \\
França & 24,74 & 27,41 & 29,31 & 29,77 & 35,32 & 33,88 & 48,25 & 53,05 & 53,82 \\
Holanda & 29,83 & 29,1 & 32,22 & 37,09 & 36,91 & 45,24 & 54,88 & 54,81 & 59,71 \\
Hungria & 31,93 & 35,55 & 26,69 & 49,14 & 44,51 & 33,10 & 72,79 & 63,24 & 49,69 \\
Itália & 24,87 & 40,13 & 30,35 & 42,26 & 43,66 & 39,84 & 58,67 & 65,67 & 64,71 \\
Noruega & 29,34 & 41,5 & 25,39 & 41,09 & 46,67 & 41,12 & 63,93 & 66,67 & 63,07 \\
Polônia & 21,00 & 23,34 & 31,99 & 27,31 & 34,26 & 36,78 & 38,91 & 44,63 & 46,55 \\
Portugal & 24,59 & 38,74 & 40,79 & 39,66 & 61,33 & 54,44 & 56,35 & 67,48 & 63,35 \\
Reino Unido & 22,27 & 29,66 & 31,08 & 22,44 & 28,04 & 29,68 & 30,33 & 31,97 & 33,05 \\
Rep. Tcheca & 38,39 & 32,37 & 28,38 & 35,54 & 44,38 & 44,12 & 51,15 & 47,47 & 48,04 \\
Suécia & 27,81 & 53,67 & 38,74 & 43,51 & 61,39 & 55,57 & 71,94 & 81,6 & 76,00 \\
Turquia & - & 34,86 & 59,59 & - & 44,38 & 53,59 & - & 57,94 & 64,12 \\
\hline Média & 32,115 & 36,751 & 35,450 & 41,359 & 45,710 & 44,080 & 58,509 & 60,802 & 60,186 \\
Desvio Padrão & 11,796 & 11,299 & 10,566 & 13,630 & 12,827 & 12,327 & 14,565 & 14,964 & 14,287 \\
\hline
\end{tabular}

Fonte: Elaboração própria, a partir de dados da CIS e PINTEC.

Também há diferença no nível de envolvimento entre os países. As PEs de Brasil, Portugal, França e Polônia são as que registraram menor envolvimento em cooperação com esses parceiros durante todo o período analisado, o que segundo Veugelers e Cassiman (2005) pode indicar maior parcela de PMEs em setores não baseados em ciência na estrutura produtiva desses países. Esse resultado vai ao encontro do verificado para o Brasil por Zucoloto e Nogueira (2016) ${ }^{3}$.

As PEs do Brasil foram as que menos se envolveram, seguidas das de Polônia, Reino Unido, Portugal, França e Itália, ainda que tenha havido melhora

\footnotetext{
${ }^{3}$ Deve-se destacar que, embora ainda muito pequenas, as interações entre empresas e universidades cresceram entre 2003 e 2011, como mostram Bastos e Britto (2011).
} 
do indicador para esses países e em 2014. Por outro lado, as PEs de Alemanha e Finlândia são as que mantiveram os maiores resultados. Mais de $50 \%$ das PEs alemãs e finlandesas realizaram cooperação com universidades entre 2008 e 2014.

As MEs e GEs da Alemanha e Finlândia também foram as que mantiveram maiores taxas no período analisado, ainda que houvesse queda na participação dessas empresas na Finlândia. As MEs e GEs do Brasil, Reino Unido e Polônia foram as que menos realizaram esse tipo de cooperação entre 2008 e 2014. Ainda que haja melhora no indicador para o Brasil, essas empresas brasileiras continuam sendo as que menos realizam cooperação com universidades. Outro resultado que chama atenção é o do Reino Unido, que apresenta elevadas taxas de cooperação para empresas de todos portes, também com pouco engajamento neste tipo de cooperação. As MEs e GEs espanholas também têm pouca participação neste tipo de cooperação.

Há grande diferença de acordo com o porte no envolvimento em cooperação com universidades para Suécia e Portugal. Estes são os países que menos se envolveram com esse tipo de parceria para as PEs, principalmente em 2008, mas estão entre os que mais se engajaram para GEs. Para a maioria dos países, há significativo aumento da participação entre 2008 e 2011, em empresas de todos os portes.

\section{- Governo}

Políticas públicas de apoio à inovação, como a formação de mão de obra especializada, a criação de institutos públicos de $\mathrm{P} \& \mathrm{D}$, a concessão de créditos fiscais ou de financiamento direto por meio de taxas de juros subsidiadas ou mesmo subvenção econômica, além de processos inteligentes de compras governamentais, são alguns dos exemplos de como o Governo pode influenciar uma empresa a realizar atividades inovativas. Sendo assim, o Governo pode, por meio de parcerias em projetos ou com formação de institutos públicos de $\mathrm{P} \& \mathrm{D}$, se tornar um parceiro no desenvolvimento de inovações. 
Tabela 8 - Empresas inovadoras que cooperam e o fazem com Governo ou institutos públicos de $P \& D$ por porte, em porcentagem

\begin{tabular}{lrrrrrrrrr}
\hline \multirow{1}{*}{ País } & \multicolumn{3}{c}{ PEs } & \multicolumn{1}{c}{ MEs } & \multicolumn{3}{c}{ GEs } \\
\cline { 2 - 10 } & $\mathbf{2 0 0 8}$ & $\mathbf{2 0 1 1}$ & $\mathbf{2 0 1 4}$ & $\mathbf{2 0 0 8}$ & $\mathbf{2 0 1 1}$ & $\mathbf{2 0 1 4}$ & $\mathbf{2 0 0 8}$ & $\mathbf{2 0 1 1}$ & $\mathbf{2 0 1 4}$ \\
\hline Alemanha & 17,53 & 38,18 & 42,19 & 20,49 & 43,11 & 44,67 & 32,08 & 52,01 & 59,91 \\
Áustria & 13,31 & 25,89 & 18,34 & 20,28 & 31,57 & 23,93 & 34,3 & 51,29 & 45,62 \\
Bélgica & 25,91 & 24,52 & 23,29 & 24,73 & 25,41 & 22,94 & 40,63 & 43,07 & 43,96 \\
Dinamarca & 24,06 & 24,31 & 11,55 & 26,13 & 26,03 & 20,80 & 36,36 & 37,87 & 37,24 \\
Espanha & 31,23 & 34,98 & 38,97 & 36,31 & 40,81 & 45,50 & 46,68 & 51,36 & 51,74 \\
Finlândia & 57,86 & 52,53 & 34,42 & 62,92 & 71,12 & 58,02 & 80,36 & 89,3 & 84,24 \\
França & 18,12 & 20,99 & 19,69 & 16,88 & 24,15 & 23,59 & 36,83 & 38,18 & 38,54 \\
Holanda & 22,67 & 21,1 & 17,49 & 24,04 & 25,57 & 20,64 & 37,67 & 38,08 & 35,94 \\
Hungria & 11,69 & 14,76 & 12,33 & 15,48 & 14,54 & 9,96 & 26,47 & 23,53 & 13,21 \\
Itália & 7,49 & 22,46 & 17,37 & 13,05 & 20,08 & 18,23 & 26,02 & 31,79 & 35,02 \\
Noruega & 34,68 & 45,35 & 25,22 & 37,46 & 49,58 & 35,33 & 60,66 & 71,43 & 60,23 \\
Polônia & 20,2 & 20,44 & 25,61 & 22,63 & 28,6 & 34,56 & 30,25 & 38,02 & 37,15 \\
Portugal & 16,47 & 31,79 & 21,80 & 25,97 & 39,36 & 28,76 & 29,76 & 40,78 & 37,17 \\
Reino Unido & 19,2 & 17,24 & 18,99 & 15,42 & 14,75 & 17,80 & 22,05 & 22,18 & 21,18 \\
Rep. Tcheca & 21,19 & 12,92 & 15,18 & 15,02 & 18,7 & 16,69 & 20,11 & 17,58 & 22,89 \\
Suécia & 17,06 & - & - & 19,39 & 38,79 & - & 32,84 & 61,6 & 55,64 \\
Turquia & - & 28,65 & 55,29 & - & 33,57 & 49,22 & - & 43,69 & 55,69 \\
\hline Média & 22,416 & 27,256 & 24,857 & 24,762 & 32,102 & 29,414 & 37,066 & 44,221 & 43,256 \\
Desvio Padrão & 11,671 & 10,937 & 12,030 & 12,366 & 14,270 & 13,714 & 15,131 & 17,994 & 17,120 \\
\hline
\end{tabular}

Fonte: Elaboração própria, a partir de dados da CIS e PINTEC.

Contudo, há uma diferença entre a PINTEC e a CIS quanto à consideração deste parceiro. A PINTEC não disponibiliza em seus questionários informações sobre cooperação com o Governo, havendo foco na questão do financiamento e incentivos fiscais, não necessariamente ligados à cooperação, não sendo possível a comparação entre empresas brasileiras e europeias ${ }^{4}$.

Dessa forma, a análise a seguir apresenta dados da $C I S$ sobre cooperação com governo e/ou institutos públicos de $\mathrm{P} \& \mathrm{D}$. O cálculo das médias aponta para uma diferença entre PEs e GEs, mas não da mesma intensidade da cooperação com empresas do mesmo grupo. As médias também apontam que para MEs esse valor é próximo de 30\% no período 2011 a 2014, sendo superior para GEs.

O desvio padrão também varia das PMEs para as GEs, sendo que as primeiras têm o menor e as GEs o maior desvio padrão. Isso é uma indicação que há maior variação de resultados de cooperação com governo para GEs, sugerindo

\footnotetext{
${ }^{4}$ A esse respeito, pode-se citar os trabalhos de Avellar e Botelho (2016; 2019). Os dois trabalhos indicam efeitos positivos do apoio governamental aos gastos com atividades inovativas das firmas industriais brasileiras.
} 
que há aspectos relacionados aos distintos SNIs em que estão inseridas que influenciam na decisão de cooperar com esse parceiro (recursos públicos mais direcionados às empresas menores, por exemplo).

Entre as PEs inovadoras que cooperam e que têm menor engajamento em cooperação com o governo estão as da Itália, Hungria e República Tcheca, em todos os períodos. Embora seja registrado uma melhora do indicador no ano de 2011, para maior a parte das PEs no ano de 2014 há piora na participação deste tipo de cooperação, como ocorreu com Dinamarca, Áustria, Hungria e Itália. As PEs finlandesas, norueguesas e espanholas são as que apresentam melhora na participação em todos os períodos analisados, e as alemãs têm aumento significativo no envolvimento com cooperação com o governo nos anos de 2011 e 2014.

Também são da Finlândia, Noruega e Espanha as médias e GEs que mais estão engajadas em realizar atividades de cooperação com o governo. As MEs italianas, húngaras, britânicas e tchecas são as que menos realizam cooperação com governo, o mesmo é observado para GEs. Há uma grande diferença do desempenho das MEs e GEs da Alemanha entre 2008 e os anos de 2011 e 2014. Para as últimas, a Alemanha apresenta aumento no período. Nesse sentido, é possível supor que as empresas alemãs reagiram ao período pós crise internacional de 2009 ampliando a cooperação com o governo e institutos públicos de P\&D.

Czarnitzki et al. (2007), trabalhando com dados da CIS para empresas alemãs e finlandesas, sugerem que políticas de incentivo à cooperação para pesquisa feitas pelo governo, em conjunto com subsídios públicos, têm efeitos positivos sobre as decisões de gastos em P\&D e nos resultados inovativos das empresas analisadas. A capacidade das empresas de absorver spillovers de conhecimento, uma vez que cooperação em pesquisa pública envolve divulgação pública de resultados, pode explicar o sucesso ou insucesso que empresas de diferentes portes podem ter na cooperação com o governo.

\section{Considerações Finais}

Este trabalho procurou contribuir para a literatura de sistemas de inovação e especificamente para a relação entre cooperação e inovação, considerando um recorte por porte da firma. Para cumprir esse objetivo, elaborou-se uma comparação entre resultados de pesquisa de inovação do Brasil e de países da União Europeia por meio da sistematização dos dados da PINTEC e CIS. 
Os resultados mostram que as diferenças dos SNIs têm influência na decisão da firma realizar cooperação, dada a discrepância entre as taxas de cooperação de países com estruturas produtivas mais complexas, como os países nórdicos (Finlândia, Noruega, Suécia, Dinamarca), Reino Unido e Bélgica, com as de países com SNIs menos desenvolvidos, como Espanha, Hungria e Brasil, embora as empresas alemãs não sigam essa regra.

Também é destacado que a taxa de cooperação varia de acordo com o porte da firma. PMEs cooperam menos que GEs em todos os países analisados, e em alguns essa diferença é consideravelmente alta, como no Brasil, Alemanha e Itália. Ainda que a cooperação seja apontada na literatura como um dos principais fatores que contribuem para o desenvolvimento de atividades inovativas, a taxa de cooperação é relativamente baixa e volátil para a maior parte das PMEs.

Embora a cooperação seja comumente identificada como uma variável capaz de contribuir para enfrentar problemas típicos do processo inovativo em PMEs, como a possibilidade de divisão dos elevados custos de atividades de $\mathrm{P} \& \mathrm{D}$, essas empresas têm menor envolvimento com cooperação. Outros resultados que podem ser destacados e que, em geral, estão em linha com achados da literatura são:

- PMEs têm grande envolvimento em cooperação vertical, ou seja, com fornecedores e consumidores. A literatura aponta que esse comportamento favorece inovações de caráter incremental e atuação em nichos de mercado pelas PMEs.

- As empresas brasileiras, de todos os portes, cooperam mais com fornecedores e consumidores do que com os demais parceiros, indicando concentração nestes tipos de cooperação, principalmente para as PMEs.

- Cooperação com empresas do mesmo grupo é aquela com diferença mais clara de engajamento entre PEs e GEs, sendo as últimas as que mais exercem esse tipo de cooperação, como é esperado.

- De modo geral, empresas da Dinamarca, Suécia e principalmente Finlândia têm as maiores taxas de cooperação com cada um dos parceiros analisados, principalmente para GEs. Isso indica que as empresas desses países têm maior diversidade de parceiros ao realizarem cooperação e são as que apresentam as maiores taxas de cooperação.

- Empresas alemãs e finlandesas são as que mais realizam cooperação com universidades ou instituições de ensino superior. É forte a presença desse 
tipo de cooperação nas PMEs destes países, quando comparada com as dos demais, ainda que em GEs esta diferença não seja tão significativa.

- Há aumento na taxa de cooperação com o Governo no período pós crise de 2008, como apresentado para os anos 2011 e 2014 em todos os países, exceto Hungria.

- A Alemanha tem baixas taxas de cooperação vertical com fornecedores e consumidores quando comparadas com os demais países, principalmente para PMEs. Essa relação se inverte na cooperação com o Governo e, principalmente, com Universidades, pois nesta as empresas alemãs têm mais engajamento que as empresas dos outros países. Esse resultado é um indício da maior presença de firmas em setores baseados em ciência no caso alemão.

Conforme foi exposto, as empresas dos países com maiores taxas de cooperação são também aquelas com maior diversidade na escolha de parceiros para inovação. GEs têm maior diversidade nas escolhas de parceiros, pois têm taxas mais elevadas de cooperação com mais parceiros. Empresas brasileiras têm indicadores mais parecidos com países com estruturas produtivas menos complexas e menores nível de renda como Portugal, Espanha, Polônia e Hungria.

Entretanto, é importante assinalar que, nos anos 2000, as empresas industriais brasileiras aumentaram a cooperação com vistas à inovação, como mostram os dados desse trabalho e os sistematizados por Bastos e Britto (2017). Esses resultados estão relacionados, provavelmente, às políticas públicas de apoio à inovação implementados na economia brasileira nos governos Lula (2003-2010) e Dilma Roussef (2010-16). Entretanto, os efeitos da recessão econômica e da desarticulação desses planos se apresentaram no último período analisado, no qual se verificou queda na atividade de cooperação. Do ponto de vista das políticas públicas, a continuidade nos programas e o gasto público contra cíclico são essenciais para que as atividades inovativas sejam o instrumento principal para a saída das crises, como mostram Filippetti e Archibugi (2011) para o caso europeu.

Entende-se que a grande quantidade de dados sistematizados neste trabalho contribui para o conhecimento dos complexos determinantes da atividade inovativa, considerando as diferenças de porte empresarial, tema ainda pouco explorado pela literatura, e de países e seus respectivos SNIs. A permanência de diferenças entre países e ao longo do período indicam que os determinantes da inovação e, em especial, a cooperação para inovação, apresenta caráter estrutural. 
Os vários parâmetros passíveis de serem analisados, como a correlação entre as características dos países e os resultados das taxas de cooperação, demandam, para investigações futuras, a adoção de técnicas de análise de dados mais sofisticadas. Também deve ser investigado, de forma mais focalizada, se há relação entre os parceiros escolhidos e os resultados da inovação, em termos de produto ou processo, vendas, ou aumento de produtividade.

\section{Referências}

ACS, Z. J.; AUDRETSCH, D. B. Innovation and small firms. Cambridge: MIT Press, 1990.

ACS, Z. J.; AUDRETSCH, D. B.; FELDMAN, M. P. R\&D spillovers and recipient firm size. The Review of Economics and Statistics, p. 336-340, 1994.

ASCHHOFF, B.; SCHMIDT, T. Empirical evidence on the success of R\&D cooperation - happy together? Review of Industrial Organization, v. 33, n. 1, p. 41-62, 2008.

AUDRETSCH, D. B. Standing on the shoulders of midgets: The US Small Business Innovation Research program (SBIR). Small Business Economics, v. 20, n. 2, 2003.

AUDRETSCH, D. B. Sustaining innovation and growth: Public policy support for entrepreneurship. Industry and Innovation, v. 11, n. 3, 2004.

AVELLAR, A. P. M.; BOTELHO, M. dos R. A. Impact of innovation policies on small, medium and large Brazilian firms. Applied Economics, v. 1, p. 1-17, 2018.

AVELlAR, A. P. M.; BOTELHO, M. dos R. A. Efeitos das políticas de inovação nos gastos com atividades inovativas das pequenas empresas brasileiras. Estudos Econômicos, v. 46, p. 609-642, 2016.

BARGE-GIL, A. Cooperation-based innovators and peripheral cooperators: An empirical analysis of their characteristics and behavior. Technovation, v. 30, n. 3 , 2010 .

BASTOS, C. P.; BRITTO, J. N. P. Inovação e geração de conhecimento científico e tecnológico no Brasil: uma análise dos dados de cooperação da Pintec segundo porte e origem de capital. Revista Brasileira de Inovação, v. 16, n. 1, 2017.

BELDERBOS, R.; CARREE, M.; LOKSHIN, B. Cooperative R\&D and firm performance. Research Policy, v. 33, n. 10, 2004. 
CASSIOlATO, J. E.; BRITTO, J. N. P.; VARGAS, Marco A. Arranjos cooperativos e inovação na indústria brasileira. Inovações, Padrões Tecnológicos e Desempenho das Firmas Industriais Brasileiras. Brasília: IPEA, 2005.

CHUN, H.; MUN, S.-B. Determinants of R\&D cooperation in small and mediumsized enterprises. Small Business Economics, v. 39, n. 2, 2012.

COHEN, W. M.; LEVINTHAL, D. A. Absorptive capacity: A new perspective on learning and innovation. Administrative Science Quarterly, 1990.

CZARNITZKI, D.; EBERSBERGER, B.; FIER, A. The relationship between R\&D collaboration, subsidies and R\&D performance: empirical evidence from Finland and Germany. Journal of Applied Econometrics, v. 22, n. 7, 2007.

FAGERBERG, J. Innovation: a guide to literature. FAGERBERG, Jan, MOWERY, David C.; NELSON, Richard. The Oxford Handbook of Innovation. Oxford: Oxford University Press, 2006.

FAGERBERG, J.; MOWERY, D. C.; NIGHTINGALE, P. Introduction: The heterogeneity of innovation - evidence from the Community Innovation Surveys. Industrial and Corporate Change, v. 21, n. 5, 2012.

FARIA, P. de; LIMA, F.; SANTOS, R. Cooperation in innovation activities: The importance of partners. Research Policy, v. 39, n. 8, 2010.

FILIPPETTI, A.; ARCHIBUGI, D. Innovation in times of crisis: National Systems of Innovation, structure, and demand. Research Policy, v. 40, n. 2, 2011.

FREEL, M. S. Barriers to product innovation in small manufacturing firms. International Small Business Journal, v. 18, n. 2, 2000.

FREEMAN, C.; SOETE, L. A economia da inovação industrial. Campinas: Editora da UNICAMP, 2008.

GRONUM, S.; VERREYNNE, M.-L.; KASTELLE, T. The role of networks in small and medium-sized enterprise innovation and firm performance. Journal of Small Business Management, v. 50, n. 2, 2012.

HAGEDOORN, J. Inter-firm R\&D partnerships: an overview of major trends and patterns since 1960. Research Policy, v. 31, n. 4, 2002.

KAUFMANN, A.; TÖDTLING, F. How effective is innovation support for SMEs? An analysis of the region of Upper Austria. Technovation, v. 22, n. 3, 2002. 
MOWERY, D. C.; SAMPAT, B. N. Universities in National Innovation Systems. In: FAGERBERG, J.; MOWERY, D. C.; NELSON, R. (Orgs.). The Oxford Handbook of innovation. Oxford: Oxford University Press, 2006.

MUSCIO, A. The impact of absorptive capacity on SME's collaboration. Economics of Innovation and New Technology, v. 16, n. 8, 2007.

NICHTER, S.; GOLDMARK, L. Small firm growth in developing countries. World development, v. 37, n. 9, p. 1453-1464, 2009.

NIETO, M. J.; SANTAMARÍA, L. Technological collaboration: Bridging the innovation gap between small and large firms. Journal of Small Business Management, v. 48, n. 1, 2010.

NOOTEBOOM, B. Innovation and diffusion in small firms: theory and evidence. Small Business Economics, v. 6, n. 5, 1994.

ROGERS, M. Networks, firm size and innovation. Small business economics, v. $22(2), 2004$.

ROTHWELL, R. Small firms, innovation and industrial change. Small Business Economics, v. 1, n. 1, 1989.

SALVADO, P.; MIRALDES, T.; FRANCO, M.; ALMEIDA, F. A. S. Barreiras à inovação em PME de base tecnológica: um estudo de caso na "Inklusion Entertainment". ALMEIDA, FAS Coletânea Luso-Brasileira. Gestão da informação, inovação e logística. Goiânia: Faculdade de tecnologia SENAI de desenvolvimento gerencial, p. 189-210, 2013.

VAONA, A.; PIANTA, M. Firm size and innovation in European manufacturing. Small business economics, v. 30, n. 3, 2008.

VERSCHOORE, J. R.; BALESTRIN, A. Ganhos competitivos das empresas em redes de cooperação. Revista de Administração USP-Eletrônica, v. 1, n. 1, 2008.

VEUGELERS, R.; CASSIMAN, B. R\&D cooperation between firms and universities. Some empirical evidence from Belgian manufacturing. International Journal of Industrial Organization, v. 23, n. 5-6, 2005.

ZUCOLOTO, G. F.; NOGUEIRA, M. O. A Dinâmica Inovativa das Empresas de Pequeno Porte no Brasil Rio de Janeiro, novembro de 2016. Texto para Discussão, 2255, IPEA, 2016.

ZENG, S. X.; XIE, X. M.; TAM, C. M. Relationship between cooperation networks and innovation performance of SMEs. Technovation, v. 30, n. 3, 2010. 